\title{
Input Sourcing and Multinational Production Online Appendix
}

\author{
Stefania Garetto
}

\section{A On Optimal Pricing in the Open Economy}

Drawing from the analogy with the auction theory literature, I show here some properties of the pricing rule that solves equation (22) in the paper.

\section{Symmetric Countries, Frictionless World}

The symmetric version of the problem $\left(\tau_{o}=\tau_{v}=1\right.$ and $m_{i}=w_{i}=w$ for $\left.i=h, f\right)$ satisfies all the conditions describing a symmetric first-price sealed-bid auction: each supplier observes his own cost (his "valuation"), but not the ones of his competitors, and costs are independently distributed according to a common density $\psi(\cdot)$ (independent private values). Moreover, the revenues in case of "win" are equal to the optimal price declared (the "bid"). McAfee and McMillan (1987) illustrate that this problem admits a Bayes-Nash equilibrium, where optimal prices are equal across countries and are given by:

$$
p(z)=w z+\frac{\int_{z}^{\infty} w p(z)^{-\eta}\left[1-\Phi\left(\frac{p(z)}{w}\right)\right][1-\Psi(\xi)] d \xi}{p(z)^{-\eta}\left[1-\Phi\left(\frac{p(z)}{w}\right)\right][1-\Psi(z)]}
$$

For Weibull-distributed costs, the optimal symmetric pricing rule $p(z)$ is a positive 
solution of:

$$
\eta w z+p(z)(1-\eta)-\vartheta p(z)^{\vartheta}[p(z)-w z]\left(\frac{\lambda}{w^{\vartheta}}+\mu\right)=0
$$

\section{Symmetric Productivities, Positive Trade and FDI Costs}

The result of the previous paragraph can be extended to the case in which trade and FDI are costly, provided that the suppliers' cost distribution is common across countries: $\Psi_{i}(\cdot)=\Psi(\cdot)$ for $i=h, f$. This introduces differences in the distribution of the marginal costs across suppliers, but these differences are deterministic, and preserve the tractability of the problem. To understand this, notice the following: in selling to market $i$, a supplier from country $j$ must charge a price $p_{i j}\left(z_{j}\right)$ which is below the price charged by the supplier in the other country. Assume here that $k=i \neq j$. This happens with probability equal to:

$$
\begin{aligned}
\operatorname{prob}\left\{p_{i j}\left(z_{j}\right) \leq p_{i k}\left(z_{k}\right)\right\} & =\operatorname{prob}\left\{\tau_{o} w_{j} z_{j} \leq w_{k} z_{k}\right\} \\
& =1-\Psi\left(\frac{\tau_{o} w_{j} z_{j}}{w_{k}}\right)
\end{aligned}
$$

Hence the optimal pricing rule can be written as:

$$
p_{i j}\left(z_{j}\right)=\tau_{o} w_{j} z_{j}+\frac{\int_{z_{j}}^{\infty} \tau_{o} w_{j} p_{i j}\left(z_{j}\right)^{-\eta}\left[1-\Phi_{i}\left(\frac{p_{i j}\left(z_{j}\right)}{m_{i}}\right)\right]\left[1-\Psi\left(\frac{\tau_{o} w_{j} \xi}{w_{k}}\right)\right] d \xi}{p_{i j}\left(z_{j}\right)^{-\eta}\left[1-\Phi\left(\frac{p_{i j}\left(z_{j}\right)}{m_{i}}\right)\right]\left[1-\Psi\left(\frac{\tau_{o} w_{j} z_{j}}{w_{k}}\right)\right]}
$$

for $i, j, k=h, f$ and $k=i \neq j$.

\section{Asymmetric Countries}

The results of the previous section cannot be extended to the case of asymmetric cost distributions $\Psi_{h}(\cdot) \neq \Psi_{f}(\cdot)$. Proofs of existence of a Bayesian Nash equilibrium in firstprice sealed-bid asymmetric auctions require the cost distributions $\Psi_{i}(\cdot)$ to be defined on a compact interval. ${ }^{1}$ For tractability reasons, I prefer not to introduce bounds on

\footnotetext{
${ }^{1}$ See Maskin and Riley (2000).
} 
the cost distributions. For each destination country $i$, I solve numerically the system of equations (22) with the following algorithm:

1. Given two initial vector of productivities $\left\{z_{h}\right\},\left\{z_{f}\right\}$, guess two initial pricing rules $p_{i j}^{0}\left(z_{j}\right)$ for each origin country $j$ to destination country $i$.

2. Compute $F_{i j}^{0}\left(p_{i j}^{0}\left(z_{j}\right)\right)$ via kernel smoothing density estimation.

3. Given $F_{i j}^{0}(\cdot)$, find the pricing rules $p_{i j}^{1}\left(z_{j}\right)(j=h, f)$ that solve $(22)$.

4. If $p_{i j}^{1}\left(z_{j}\right)-p_{i j}^{0}\left(z_{j}\right)<\varepsilon, \forall j$, STOP.

If $p_{i j}^{1}\left(z_{j}\right)-p_{i j}^{0}\left(z_{j}\right) \geq \varepsilon, \forall j$, compute $F_{i j}^{1}\left(p_{i j}^{1}\left(z_{j}\right)\right)$, and continue iterating until convergence.

If a solution exist, it must lie between the marginal cost and the closed-economy pricing rule. I use the perfectly competitive pricing rules to initialize the algorithm.

\section{B On the Computation of the Price Indexes}

In this short Appendix I explain how to compute the price indexes in the model. This computation is non-standard because the non-linearity of the pricing rules implies that equations (18)-(19) do not admit a closed form solution for Weibull cost distributions.

When one cannot solve for the price indexes in closed form, a Gaussian quadrature rule is the most efficient way of computing them. The nodes and weights that define a Gaussian quadrature depend on orthogonal polynomials, and classical orthogonal polynomials do not exist for the Weibull measure. In order to generate the nodes and weights to construct the quadrature, I follow the extended polynomial dimensional decomposition method developed by Rahman (2009). ${ }^{2}$

I construct the Weibull quadrature using 15 nodes. This is a large number, justified by the fact that the integrand function is not itself a polynomial: with a large number of

\footnotetext{
${ }^{2}$ I am indebted to Sharif Rahman for sharing the codes to compute the optimal nodes and weights for the Weibull measure.
} 
nodes, I essentially approximate a non-polynomial function in the integrand by higher-order polynomials.

\section{Input Differentiation and Intrafirm Trade: Data Con- struction and Sources}

\section{C.1 Intrafirm Import Shares}

Intrafirm import shares at the sector level are constructed combining data on intrafirm import from the Bureau of Economic Analysis (B.E.A.) and data on total U.S. imports by sector available from the Center of International Data at U.C. Davis. ${ }^{3}$

Consistently with the theory, I restrict the analysis to intrafirm trade of the "vertical" type: the variable of interest is "Imports Shipped by Affiliates - Shipped to U.S. parents", indicating production in offshore majority-owned affiliates that is destined to the home market. Data on intrafirm imports by sector are available for 34 B.E.A. manufacturing sectors, roughly corresponding to the 204-390 ISI industries. I exclude natural resources industries (Primary Metal Industries, Ferrous and Non-Ferrous) and those sectors for which the data are missing (Tobacco Products, Leather and Leather Products, and Other Paper and Allied Products). I end up with 29 industries for the years 1983-1998. Intrafirm import shares exhibit a lot of variation across sectors: from a minimum of 0.3 percent for Apparel and Other Textile Products in 1987 to a maximum of 93.13 percent for Farm and Garden Machinery in 1988.

Starting in 1999, the industry classification becomes less detailed: thirteen sectors are merged into six, so I end up with 22 industries for the years 1999-2005. Appendix D shows that the results of the regressions in the paper are robust to the choice of the sample period.

\footnotetext{
${ }^{3}$ See Bureau of Economic Analysis (1983-2005) and Feenstra (1972-2006).
} 


\section{C.2 Measures of Sector Differentiation}

The construction of the dummy variable $D_{B E A_{s}}^{\eta}$ as used in the baseline regressions is described in equation (31) in the paper. Table D.1 reports the values of $D_{B E A_{s}}^{\eta}$ for the first and last year of the main sample period: 1983 and 1998. Notice that the value of $D_{B E A_{s}}^{\eta}$ changes from year to year only due to different weighting in the aggregation from SITC to B.E.A. sectors: import shares change over time, but the Broda and Weinstein (2006) estimates do not.

\begin{tabular}{llll}
\hline \hline & & & \\
Code & Description & $D_{B E A_{s}}^{\eta}(1983)$ & $D_{B E A_{s}}^{\eta}(1998)$ \\
\hline & & & \\
1 & Grain, Mill and Bakery Products & 0 & 0 \\
2 & Beverages & 0 & 0 \\
4 & Other Food and Kindred Products & 0.3785 & 0.4698 \\
5 & Apparel and Other Textile Products & 0.6079 & 0.5049 \\
7 & Pulp, Paper and Boardmills & 0 & 0 \\
9 & Printing and Publishing & 0.9194 & 0.8648 \\
10 & Drugs & 1 & 1 \\
11 & Soaps, Cleaners and Toilet Goods & 0.6312 & 0.7332 \\
12 & Agricultural Chemicals & 0.3239 & 0.3596 \\
13 & Industrial Chemicals and Synthetics & 0.2672 & 0.5207 \\
14 & Other Chemicals & 1 & 1 \\
15 & Rubber Products & 0.9674 & 0.8834 \\
16 & Miscellaneous Plastic Products & 0.1569 & 0.1605 \\
19 & Fabricated Metal Products & 0.4925 & 0.3941 \\
20 & Farm and Garden Machinery & 1 & 1 \\
21 & Construction, Mining, etc. & 0.3875 & 0.4983 \\
22 & Computer and Office Equipment & 1 & 0.3996 \\
23 & Other Nonelectric Machinery & 0.6622 & 0.6014 \\
24 & Household Appliances & 1 & 1 \\
25 & Household Audio and Video, etc. & 0.8197 & 0.7605 \\
26 & Electronic Components & 1 & 1 \\
27 & Other Electrical Machinery & 0.5059 & 0.5039 \\
28 & Motor Vehicles and Equipment & 0.6462 & 0.6207 \\
29 & Other Transportation Equipment & 0.5349 & 0.3194 \\
30 & Lumber, Wood, Furniture, etc. & 0.0323 & 0.5837 \\
31 & Glass Products & 0.4395 & 0.5399 \\
32 & Stone, Clay, Concrete, Gipsum, etc. & 0.8445 & 0.8232 \\
33 & Instruments and Apparatus & 0.9791 & 0.9717 \\
34 & Other Manufacturing & 0.6726 & 0.5154 \\
\hline \hline & & & \\
& & & \\
\end{tabular}

Table D.1: Sector differentiation variable, baseline specification. 
One could argue that this dummy is too coarse to capture the variation across the elasticities of substitution estimated by Broda and Weinstein (2006). For robustness, I run the same regression with the differentiation variable $D_{B E A_{s}}^{\eta}$ constructed as follows:

$$
D_{B E A_{s}}^{\eta}=\exp \left\{\sum_{S I T C_{s} \in B E A_{s}} \frac{\text { import }_{S I T C_{s}}}{\text { import }_{B E A_{s}}} \times \log \left(\eta_{S I T C_{s}}\right)\right\}
$$

where $\eta_{\text {SITC }}$ denotes the actual estimate of the elasticity of substitution at the SITC 3-digit level from Broda and Weinstein (2006). The proposed aggregation across sectors smoothes out outliers in the estimates and reduces issues of measurement error. The results of the regressions using this measure of differentiation are reported in Appendix D.

Alternatively, one could argue that the results are not robust to other ways of defining differentiation, not based on Broda and Weinstein (2006)'s estimates. To address this concern, I construct a differentiation variable based on an alternative classification. Rauch (1999) classified goods at the 4-digit SITC level in three categories: homogeneous goods or commodities (if traded in organized exchanges), reference priced goods (if they have price quotations reported in trade journals), and differentiated goods (if they could not be priced in either of these ways). To construct the differentiation variable, I define a dummy variable

$D_{\text {Rauch } \text { SITC }_{s}}^{\eta}$ that assigns value 0 to homogeneous goods, value 0.5 to reference priced goods and value 1 to differentiated products. $D_{\text {Rauch } \text { SITC }_{s}}^{\eta}$ is aggregated to the B.E.A. classification level following the same weighting scheme as in the paper. The results of the regressions using the Rauch-based measure of differentiation are also reported in Appendix D.

\section{C.3 Other Controls}

Data sources and construction methods for the controls entering the regressions follow closely the description in Antràs (2003). Capital intensity, human capital intensity, and value added as a share of sales are constructed using data from the NBER Productivity Database. R\&D intensity and advertising intensity are obtained from a 1977 FTC Survey. Capital stock per establishment, to be interpreted as a measure of scale, is constructed by combining 
capital stock figures from the NBER Productivity Database with data on the number of establishments per industry published by the U.S. Census Bureau in the County Business Patterns series.

\section{Input Differentiation and Intrafirm Trade: Robust- ness}

I report results of alternative specifications of the regressions in the paper, testing the robustness of the results to the construction methodology of the differentiation variable and to the choice of the time period.

\section{D.1 Alternative Specifications of $D_{B E A_{s}}^{\eta}$}

Table E.1 shows the results of the regressions with the differentiation variable constructed using the actual values of Broda and Weinstein (2006)'s estimates as described in equation (D.1).

Using the estimated elasticities implies that small (large) values of $D_{B E A_{s}}^{\eta}$ are associated to more (less) differentiation, so we should expect a negative coefficient $\hat{\beta}_{1}$ in these regressions. Values of the estimated parameters and significance levels differ from the baseline specification, but it is worthy to notice that the coefficient on the differentiation variable is negative across specifications and significant at the 5 percent significance level in the most inclusive specification in column (7).

Table E.2 shows the results of the regressions with the differentiation dummy constructed according to Rauch (1999)'s classification, as explained in Appendix C.

Like in the baseline specification, the construction of the differentiation dummy using Rauch (1999)'s classification implies that large (small) values of $D_{B E A_{s}}^{\eta}$ are associated to

more (less) differentiation, so we should expect a positive coefficient $\hat{\beta}_{1}$ in these regressions. 


\begin{tabular}{|c|c|c|c|c|c|c|c|}
\hline & (1) & $(2)$ & (3) & $(4)$ & $(5)$ & (6) & (7) \\
\hline$D_{B E A_{s}}^{\eta}$ & $\begin{array}{l}-0.013 \\
(0.039)\end{array}$ & $\begin{array}{c}-0.084 \\
(0.036)^{* *}\end{array}$ & $\begin{array}{l}-0.060 \\
(0.038)\end{array}$ & $\begin{array}{l}-0.063 \\
(0.037)^{*}\end{array}$ & $\begin{array}{l}-0.062 \\
(0.036)^{*}\end{array}$ & $\begin{array}{l}-0.050 \\
(0.041)\end{array}$ & $\begin{array}{l}-0.088 \\
(0.040)^{* *}\end{array}$ \\
\hline $\ln (K / L)_{s}$ & & $\begin{array}{c}0.891 \\
(0.312)^{* * *}\end{array}$ & $\begin{array}{c}0.728 \\
(0.304)^{* *}\end{array}$ & $\begin{array}{c}0.691 \\
(0.306)^{* *}\end{array}$ & $\begin{array}{c}0.733 \\
(0.348)^{* *}\end{array}$ & $\begin{array}{c}0.760 \\
(0.348)^{* *}\end{array}$ & $\begin{array}{l}0.184 \\
(0.643)\end{array}$ \\
\hline $\ln (H / L)_{s}$ & & & $\begin{array}{c}0.412 \\
(0.305)\end{array}$ & $\begin{array}{c}0.466 \\
(0.326)\end{array}$ & $\begin{array}{c}0.474 \\
(0.314)\end{array}$ & $\begin{array}{c}0.436 \\
(0.260)^{*}\end{array}$ & $\begin{array}{l}0.209 \\
(0.252)\end{array}$ \\
\hline $\ln (V A / \text { sales })_{s}$ & & & & $\begin{array}{l}-0.260 \\
(0.874)\end{array}$ & $\begin{array}{l}-0.240 \\
(0.848)\end{array}$ & $\begin{array}{l}-0.230 \\
(0.751)\end{array}$ & $\begin{array}{l}-0.742 \\
(0.814)\end{array}$ \\
\hline $\ln (\text { ADV/sales })_{s}$ & & & & & $\begin{array}{l}-0.080 \\
(0.169)\end{array}$ & $\begin{array}{l}-0.054 \\
(0.148)\end{array}$ & $\begin{array}{l}-0.081 \\
(0.157)\end{array}$ \\
\hline $\ln (R \& D / \text { sales })_{s}$ & & & & & & $\begin{array}{c}0.238 \\
(0.173)\end{array}$ & $\begin{array}{l}0.268 \\
(0.179)\end{array}$ \\
\hline $\ln (K / N)_{s}$ & & & & & & & $\begin{array}{l}0.723 \\
(0.491)\end{array}$ \\
\hline $\begin{array}{l}\text { No. of obs. } \\
\text { adj. } R^{2}\end{array}$ & $\begin{array}{c}458 \\
0.0008\end{array}$ & $\begin{array}{c}458 \\
0.213\end{array}$ & $\begin{array}{c}458 \\
0.256\end{array}$ & $\begin{array}{c}458 \\
0.257\end{array}$ & $\begin{array}{c}458 \\
0.262\end{array}$ & $\begin{array}{c}458 \\
0.296\end{array}$ & $\begin{array}{c}145 \\
0.387\end{array}$ \\
\hline
\end{tabular}

Table E.1: Regressions of intrafirm import shares on a measure of differentiation and other controls. Differentiation variable constructed using the values of Broda and Weinstein (2006)'s estimates.

Also here values of the estimated parameters and significance levels differ from the previous specifications, but the coefficient on the differentiation variable is positive across specifications and significant at the 1 percent significance level in the most inclusive specification in column (7).

\section{D.2 Alternative Sample Period}

Starting in 1999, the industry classification in the B.E.A. data becomes even less detailed: thirteen of the sectors are merged into only six sectors, so I end up with 22 industries for the years 1999-2005. Particularly, this coarser industry classification merges sectors that are characterized by very different degrees of differentiation: most notably, sector 15 (Rubber Products, a sector with very low estimated elasticities) is merged with sector 16 (Miscellaneous Plastic Products, a sector with high estimated elasticities), and sector 20 


\begin{tabular}{|c|c|c|c|c|c|c|c|}
\hline & (1) & $(2)$ & (3) & (4) & $(5)$ & (6) & $(7)$ \\
\hline$D_{B E A_{s}}^{\eta}$ & $\begin{array}{c}0.308 \\
(0.935)\end{array}$ & $\begin{array}{l}1.405 \\
(1.084)\end{array}$ & $\begin{array}{c}1.720 \\
(0.852)^{* *}\end{array}$ & $\begin{array}{c}1.940 \\
(0.869)^{* *}\end{array}$ & $\begin{array}{c}1.927 \\
(0.870)^{* *}\end{array}$ & $\begin{array}{c}1.731 \\
(0.904)^{*}\end{array}$ & $\begin{array}{c}2.256 \\
(0.837)^{* * *}\end{array}$ \\
\hline $\ln (K / L)_{s}$ & & $\begin{array}{c}0.972 \\
(0.291)^{* * *}\end{array}$ & $\begin{array}{c}0.831 \\
(0.279)^{* * *}\end{array}$ & $\begin{array}{c}0.735 \\
(0.267)^{* * *}\end{array}$ & $\begin{array}{c}0.771 \\
(0.280)^{* * *}\end{array}$ & $\begin{array}{c}0.789 \\
(0.287)^{* * *}\end{array}$ & $\begin{array}{c}0.336 \\
(0.476)\end{array}$ \\
\hline $\ln (H / L)_{s}$ & & & $\begin{array}{c}0.579 \\
(0.283)^{* *}\end{array}$ & $\begin{array}{c}0.760 \\
(0.302)^{* *}\end{array}$ & $\begin{array}{c}0.766 \\
(0.292)^{* * *}\end{array}$ & $\begin{array}{c}0.709 \\
(0.276)^{* *}\end{array}$ & $\begin{array}{c}0.567 \\
(0.242)^{* *}\end{array}$ \\
\hline $\ln (\text { VA/sales })_{s}$ & & & & $\begin{array}{l}-0.772 \\
(0.712)\end{array}$ & $\begin{array}{l}-0.751 \\
(0.701)\end{array}$ & $\begin{array}{c}-0.696 \\
(0.701)\end{array}$ & $\begin{array}{c}-1.426 \\
(0.684)^{* *}\end{array}$ \\
\hline $\ln (A D V / \text { sales })_{s}$ & & & & & $\begin{array}{l}-.071 \\
(0.150)\end{array}$ & $\begin{array}{l}-0.053 \\
(0.135)\end{array}$ & $\begin{array}{c}-0.049 \\
(0.149)\end{array}$ \\
\hline $\ln (R \& D / \text { sales })_{s}$ & & & & & & $\begin{array}{c}0.164 \\
(0.165)\end{array}$ & $\begin{array}{c}0.165 \\
(0.178)\end{array}$ \\
\hline $\ln (K / N)_{s}$ & & & & & & & $\begin{array}{c}0.586 \\
(0.422)\end{array}$ \\
\hline $\begin{array}{l}\text { No. of obs. } \\
\text { adj. } R^{2}\end{array}$ & $\begin{array}{c}458 \\
0.003\end{array}$ & $\begin{array}{c}458 \\
0.242\end{array}$ & $\begin{array}{c}458 \\
0.328\end{array}$ & $\begin{array}{c}458 \\
0.343\end{array}$ & $\begin{array}{c}458 \\
0.346\end{array}$ & $\begin{array}{c}458 \\
0.362\end{array}$ & $\begin{array}{c}145 \\
0.476\end{array}$ \\
\hline
\end{tabular}

Table E.2: Regressions of intrafirm import shares on a measure of differentiation and other controls. Differentiation variable constructed using Rauch (1999)'s classification.

(Farm and Garden Machinery, a sector with very low estimated elasticities) is merged with sector 21 (Construction and Mining, a sector with relatively high estimated elasticities). Table E.3 shows the results of the regressions run for the more recent sample period 19992005.

Due to the coarser classification of sectors the results are not as robust as in the baseline sample period, but the coefficient on the differentiation variable is positive across specifications and significant at the 1 percent significance level in all specifications except the most inclusive one.

\section{References}

Antràs, Pol. 2003. "Firms, Contracts, and Trade Structure." Quarterly Journal of Economics, 118(4): 1375-1418. 


\begin{tabular}{|c|c|c|c|c|c|c|c|}
\hline & $(1)$ & $(2)$ & $(3)$ & $(4)$ & $(5)$ & $(6)$ & $(7)$ \\
\hline$D_{B E A_{s}}^{\eta}$ & $\begin{array}{c}1.456 \\
(0.528)^{* * *}\end{array}$ & & $\begin{array}{c}1.631 \\
(0.416)^{* * *}\end{array}$ & $\begin{array}{c}1.653 \\
(0.430)^{* * *}\end{array}$ & $\begin{array}{c}1.822 \\
(0.411)^{* * *}\end{array}$ & $\begin{array}{c}1.798 \\
(0.417)^{* * *}\end{array}$ & $\begin{array}{c}.775 \\
(0.778)\end{array}$ \\
\hline $\ln (K / L)_{s}$ & & $\begin{array}{c}0.632 \\
(0.487)\end{array}$ & $\begin{array}{c}0.739 \\
(0.458)\end{array}$ & $\begin{array}{c}0.812 \\
(0.588)\end{array}$ & $\begin{array}{c}0.668 \\
(0.572)\end{array}$ & $\begin{array}{c}0.657 \\
(0.610)\end{array}$ & $\begin{array}{l}0.125 \\
(0.562)\end{array}$ \\
\hline $\ln (H / L)_{s}$ & & & & $\begin{array}{l}-0.124 \\
(0.429)\end{array}$ & $\begin{array}{c}0.141 \\
(0.375)\end{array}$ & $\begin{array}{c}0.136 \\
(0.380)\end{array}$ & $\begin{array}{l}-0.410 \\
(0.379)\end{array}$ \\
\hline $\ln (V A / \text { sales })_{s}$ & & & & & $\begin{array}{r}-1.415 \\
(0.958)\end{array}$ & $\begin{array}{r}-1.432 \\
(0.921)\end{array}$ & $\begin{array}{c}-1.623 \\
(0.672)^{* *}\end{array}$ \\
\hline $\ln (A D V / \text { sales })_{s}$ & & & & & & $\begin{array}{c}0.037 \\
(0.200)\end{array}$ & $\begin{array}{c}0.275 \\
(0.207)\end{array}$ \\
\hline $\ln (\text { R\&D/sales })_{s}$ & & & & & & & $\begin{array}{c}0.851 \\
(0.324)^{* * *}\end{array}$ \\
\hline No. of obs & 154 & 154 & 154 & 154 & 154 & 154 & 154 \\
\hline adj. $R^{2}$ & 0.155 & 0.106 & 0.298 & 0.301 & 0.347 & 0.348 & 0.526 \\
\hline
\end{tabular}

Table E.3: Regressions of intrafirm import shares on a measure of differentiation and other controls: 1999-2005.

Broda, Christian, and David E. Weinstein. 2006. "Globalization and the Gains from Variety." Quarterly Journal of Economics, 121(2): 541-585.

Bureau of Economic Analysis. 1983-2005. "U.S. Direct Investment Abroad: Operations of U.S. Parent Companies and Their Foreign Affiliates. Comprehensive financial and operating data." U.S. Department of Commerce, Washington, D.C., http://www.bea.gov/international/di1usdop.htm.

Feenstra, Robert C. 1972-2006. "U.S. Import and Export Data. Center for International Data at U.C. Davis." http://cid.econ.ucdavis.edu/.

Maskin, Eric, and John Riley. 2000. "Equilibrium in Sealed High Bid Auctions." Review of Economic Studies, 67(3): 439-454.

McAfee, Preston, and John McMillan. 1987. "Auctions and Bidding." Journal of Economic Literature, 25(2): 699-738. 
Rahman, Sharif. 2009. "Extended Polynomial Dimensional Decomposition for Arbitrary Probability Distributions." Journal of Engineering Mechanics, 135(12): 1439-1451.

Rauch, James E. 1999. "Networks Versus Markets in International Trade." Journal of International Economics, 48: 7-35. 